\title{
DIFFICULTIES IN THE MICROSURGICAL TREATMENT OF GIANT AND COMPLEX ANEURYSMS OF THE ANTERIOR CIRCULATION OF THE CIRCLE OF WILLIS: PROPOSAL OF A TECHNICAL AND PROGNOSTIC SCALE (ABSTRACT)* THESIS. SÃO PAULO, 2005.
}

\author{
JOSÉ FERNANDO GUEDES CORRÊA**
}

Giant ( $25 \mathrm{~mm}$ in diameter or larger) and complex (20 to $24 \mathrm{~mm}$ in diameter) intracranial aneurysms are severe lesions with high morbidity and mortality rates when left untreated. It is a recognized fact in the few surgical series published that, due to its rarity ( $2 \%$ e $7 \%$ of all intracranial aneurysms), few surgeons have effective experience with such lesions. Among the various techniques used to this date, the one considered most effective and durable for treating these aneurysms is the occlusion and clipping of the aneurysm neck using metal clips, preserving the afferent and efferent vasculature, thus completely excluding the aneurysm sac from the circulation. Another advantage of this technique is the possibility of emptying the aneurysm of thrombotic material, thereby decreasing the pseudotumor syndrome in encephalic structures. Although the literature identifies specific complexities in microsurgery with regards to clipping these aneurysms, there is no systematization or quantification of the anatomic and surgical details responsible for a higher degree of surgical difficulty and the probability of bad surgical results. The purpose of this study was to develop and verify the applicability of a technical prognostic scale of the difficulties in the microsurgical treatment of giant and complex aneurysms of the anterior circulation of the Circle of Willis, developed and applied in 50 operated aneurysms.

Thus, a scale was developed in which 8 variants were considered. i) types of craniotomy: whether standard (clas- sic frontotemporalsphenoidal) or extended; ii) resection of the anterior clinoid process; iii) topographic location of the aneurysm in the artery; iv) larger aneurysm diameter (from 20 $\mathrm{mm}$ to $24 \mathrm{~mm}$, or $25 \mathrm{~mm}$ in diameter or (arger); v) adhesion of the lesion to the parenchyma, neurovascular structures or osteodural elements; vi) the presence of lobulations; vii) neck (access, diameter, the presence of calcium deposits or atheroma and the presence of vessels adhered to/included into the aneurysm neck) and viii) contents of the aneurysm (thrombosis). A numeric amount was given to each variant. By adding each amount for each variant, a score (from 1 to 14) is achieved, for each of the 50 surgeries.

Therefore, two groups were established: difficult surgery (scores from 1 to 8 ) and extremely difficult surgery (scores from 9 to 14). For a statistical assessment, comparing both groups in relation to the various demographic and clinical variants collected during the study, the Pearson chi-square test was performed, with a correction for continuity. In those cases with less than 5 patients in a given band, the exact version of the test was used. Considering the results, it was concluded that the proposed scale is useful in preoperative, intraoperative and prognostic planning of microsurgery for giant and complex aneurysms in the anterior circulation of the Circle af Willis.

Key words: intracranial aneurysm, microcisurrgery, prognos tics, cerebral hemorrhage, cerebral arteries, abnormalities, anatomy, histology.

*Dificuldades no tratamento microcirúrgico dos aneurismas gigantes e complexos da circulação anterior do polígono de Willis: proposta de escala técnica prognostica (Resumo). Tese de Doutorado, Faculdade de Medicina da Universidade de São Paulo (Área: Clínica Cirúrgica). Orientador: Erasmo Magalhães Castro de Tolosa.

**Address: Rua Jardim Botânico 700 / 407 - 22461-000 Rio de Janeiro RJ - Brasil (E-mail: unirioneurosurg@gmail.com). 